\title{
3 BresCla Food for Thought: A Scan of Rural School Food Environments
}

Bissan Ghaith, Dietetic Intern 2017-2018 Diploma in Dietetic Education \& Practical Training, Brescia University College. Supported by: Laura Needham, RD, Kathryn Forsyth, RD, Lynda Bumstead, RD

Introduction:

\section{What does the Food Environment refer to?}

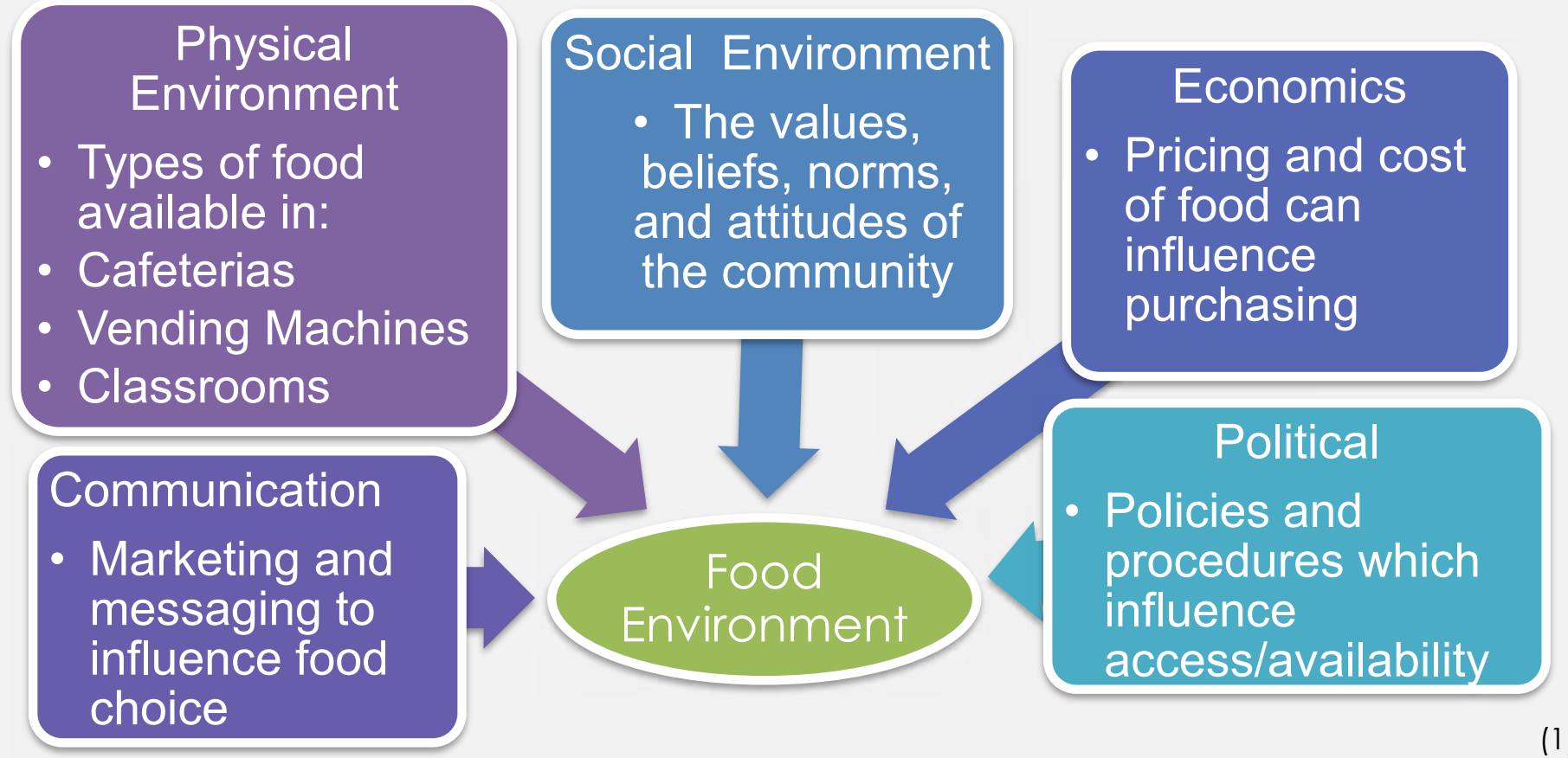

$>$ Only 1 in 4 Grey Bruce students consume sufficient fruits and vegetables and forty percent have reported eating junk foods more than four times a day (2).

> The 2004 Canadian Community Health Survey indicates that children are not meeting the minimum daily servings of fruits and vegetables and only 1 in 10 Canadian youth are meeting the fruit and vegetable recommendations (3).

$>$ Elementary and secondary students consume about one-third of their calories at school (4).

$>$ Recent reviews indicate a strong correlation between overall diet quality and academic performance in school-aged children and adolescents. Children from socioeconomically disadvantaged families performed more poorly than others (5).

\section{Methods:}

$>$ Study Design: Mixed-methods approach:14 semi-structured interviews were conducted ( $n=18)$. Participants included principals, faculty, volunteers, and parents at schools in the Bruce-Grey Catholic District School Board and Conseil Scolaire Catholique Providence. Following each interview, an environmental scan was completed using a tool adapted from Alberta Health Science's Healthy Eating Rubric, and Nutrition Tools for Schools: Creating a Healthy School Nutrition Environment.

> Data Analysis: An iterative approach and thematic content analysis was used to identify and categorize emergent themes in the collected data.

\section{Results:}

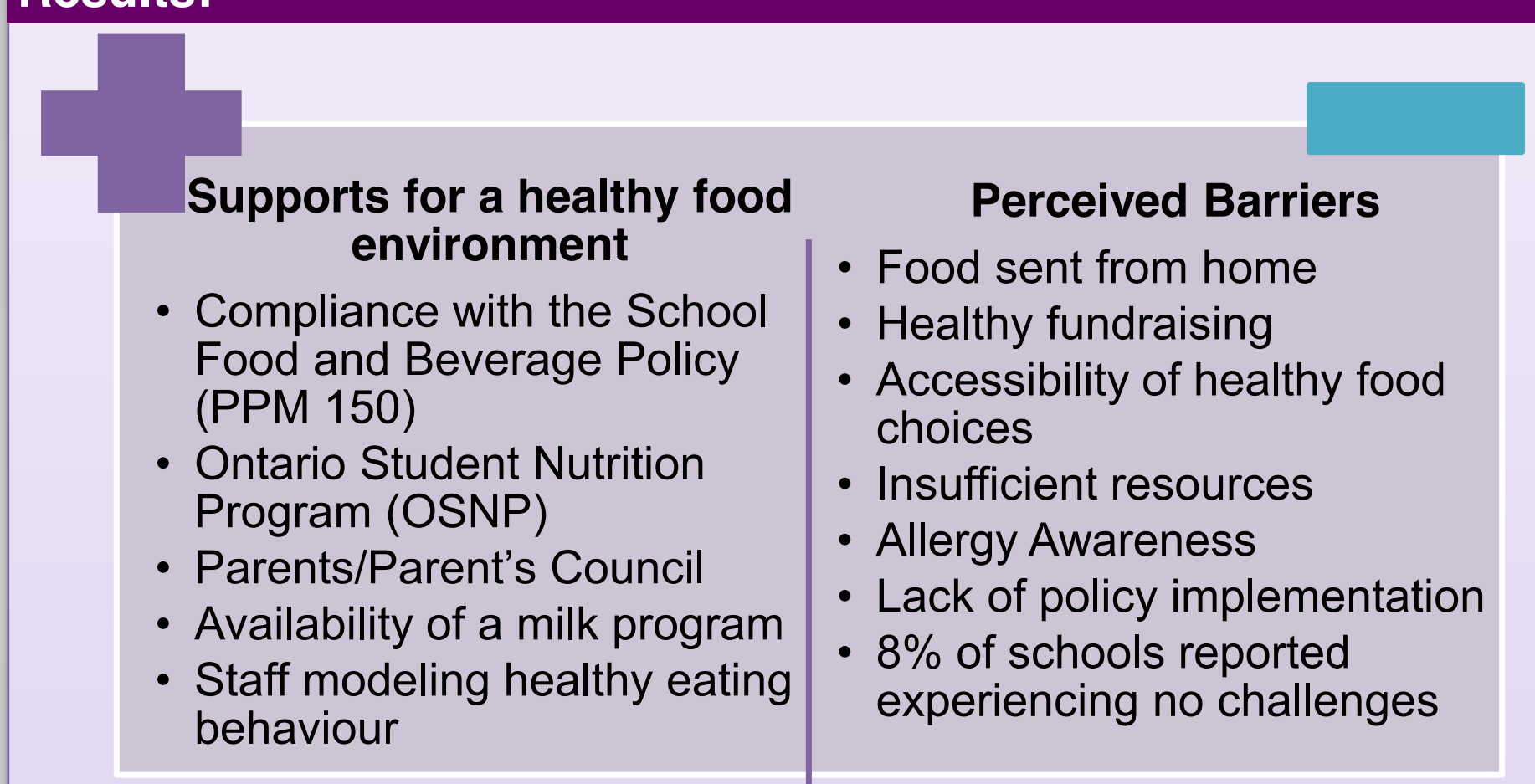

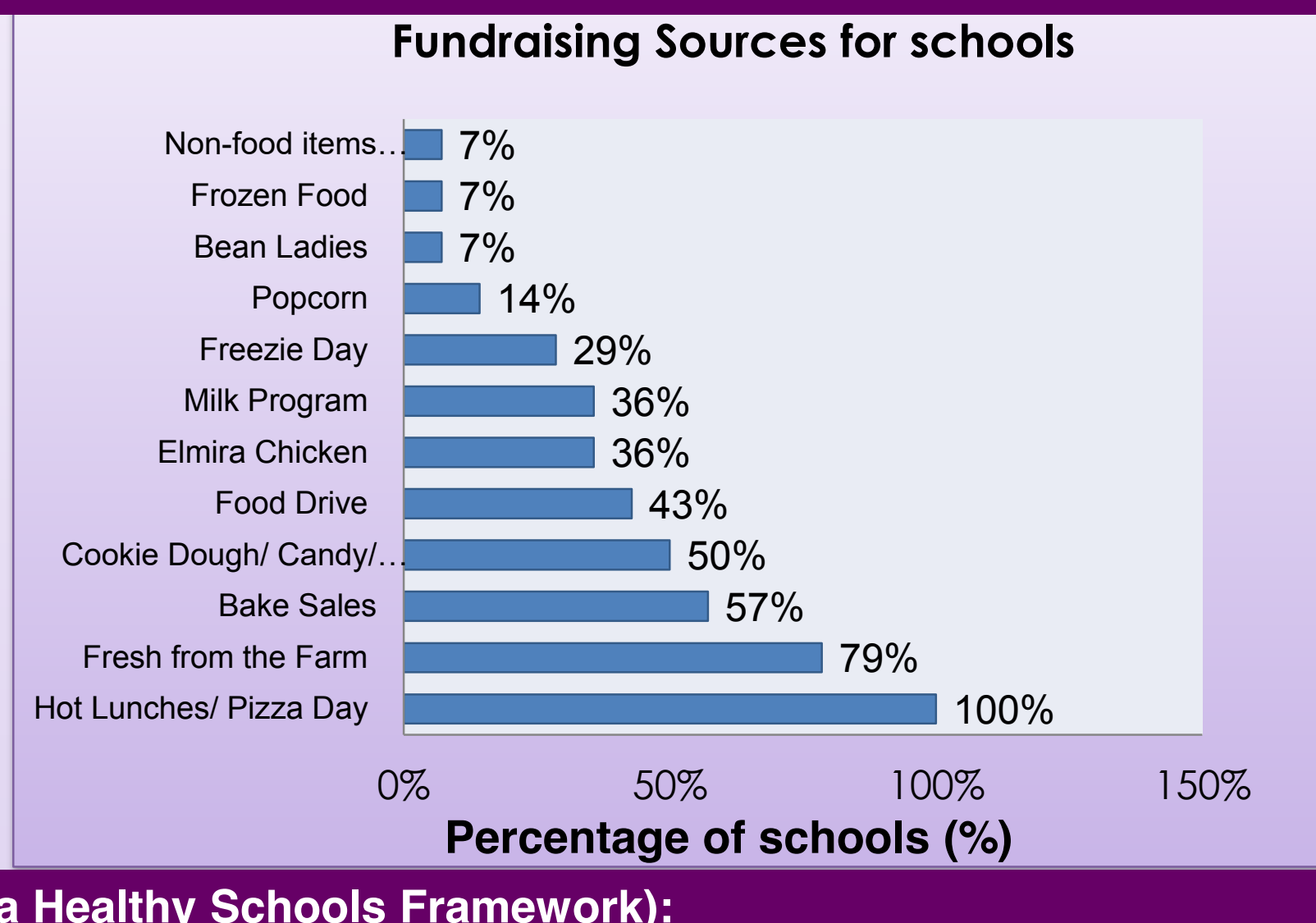

\section{Conclusions and Recommendations (Based on the Foundations for a Healthy Schools Framework):}

\section{Curriculum, Teaching, \& Learning}

$>$ Schools and public health organize regular meetings to discuss opportunities to promote nutrition and address concerns. Consider offering training sessions on nutrition concepts and resources to staff, encouraging consistent messaging across all schools.

II. School \& Classroom Leadership

$>$ Schools in this study which had a designated school champion had a higher likelihood of having a supportive school food environment. Create a dedicated position for an individual or group who will take the lead on health and nutrition initiatives and activities.

\section{III.Student Engagement}

$>$ Engage students in decisions relating to school nutrition by getting their feedback on school lunches, offering cooking classes and healthy options in the school environment.

$>$ Inspire students through a friendly competition of earning badges and a chance of being featured in the Hall of Fame. Visit Bright Bites (brightbites.ca) to learn more.

\section{Social \& Physical Environment}

$>$ Use tools such as the Healthy Schools Toolkit, the Healthy School Planner, or Bright Bites to evaluate the food environment in classrooms, playgrounds, and hallways.

> Use non-food items, such as T-shirts, or magazines, for healthy fundraising.

V. Home, School, and Community Partnerships

$>$ Send nutrition handouts from trusted sources to parents to help with selecting and preparing healthy lunches and snacks.

> Use technology! Connect to parents/guardians through smartphone applications such as "Remind", or social media to send out nutrition promotions or surveys to facilitate collaboration on nutrition/health goals.

VI. Support for Indigenous inclusion

$>$ Highlight Indigenous food traditions and customs through curriculum or through collaborative community projects. Initiatives undertaken by participating schools that may be adapted include: sharing an Indigenous phrase of the day, creating a wall in tribute of the missing and murdered Indigenous women, and hosting a year end Pow-Wow.

\section{References:}

1) Forsyth K, Labonte D, Neil K, McMillan H, Smith D. Getting Started with Healthy Eating in Your Recreation Setting [Internet]. Toronto (ON): Nutrition Resource Centre at Ontario Public Health Association and Ontario Society for Nutrition Professionals in Public Health; 2017 May 25.45 Supported by the Government of Ontario. Available from:

https://www.publichealthgrevbruce.on.ca/Portals///Topics/Eating\%20Well/NRC OSNPPH HE-rec-setting.pdf 2018 April 16]. Available from: https://www.publichealthgrevbruce.on.ca/Portals/0/Topics/HealthvCommunities/Attachmen Statistics Canada [Internet]. [2016 Sept 08; cited 2018 Apr 16]. Fruit and Vegetable Consumption; [about 1 screen]. Available fron https://www.statcan.gc.ca/pub/82-229-x/2009001/deter/fvc-eng.htm

(

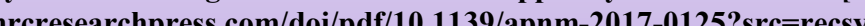
.

\section{Acknowledgments:}

I would first like to send my deepest gratitude to the Population Health Team at the Grey Bruce Health Unit for all the support and encouragement provided. Thank you to the school boards and participants who dedicated time to contribute to this research project. A special thank you to Brescia's Internship Coordinator for assigning me with this special project. Finally, this project would not have been possible without my exceptional preceptors, thank you immensely! 